\title{
An In-Vitro Study of the Antibacterial Efficacy of Cavity Liners Against Streptococcus Mutans and Lactobacillus Casei
}

KazerooniZadeh $\mathbf{N}^{1}$, Kazemian $\mathbf{M}^{2}$,Mirzakoochaki borojen $\mathbf{P}^{2^{*}}$

1.Post-Graduate student, Operative dentistry Dept, faculty of dentistry, Isfahan (Khorasgan) branch, Islamic Azad university, Isfahan, Iran 2.Assistant professor, Operative dentistry Dept, faculty of dentistry, Isfahan (Khorasgan) branch, Islamic Azad university, Isfahan , Iran

\begin{tabular}{l}
\hline ARTICLE INFO \\
\hline Article Type \\
Original Article \\
Article History \\
Received: Jan 2017 \\
Accepted:Feb 2017 \\
ePublished: Apr 2017 \\
\hline Keywords: \\
Dental cavity liners, \\
Antibacterial activity, \\
Streptococcus mutans, \\
Lactobacillus casei, \\
Fluoride-releasing restorative \\
dental materials
\end{tabular}
dental materials

\section{ABSTRACT}

\begin{abstract}
Background and aim: The main factor that influences the durability of dental restorations is secondary caries. Antibacterial activity of dental materials is important from the clinical aspect, as it might inhibit recurrent caries. The aim of the present study was to compare the antibacterial activity of four fluoride-releasing dental cavity liners against Streptococcus mutans (S. mutans) and Lactobacillus casei (L. casei).

Materials and methods: In this experimental in-vitro study, the agar diffusion test was used to compare the antibacterial efficacy of four dental cavity liners against S. mutans and L. casei. Indicator strains of S. mutans (ATCC35668) and L. casei (ATCC393) were obtained in the form of lyophilized culture. They were grown separately in $15 \mathrm{ml}$ of Brain Heart Infusion (BHI) agar at $37^{\circ} \mathrm{C}$ for 48 hours. Antibacterial activities of Ionobond (VOCO), Ionoseal (VOCO), Ionosit (DMG), and Vitrebond (3M) dental cavity liners were evaluated at 24 and 48 hours and at 7 days by measuring the diameter of the inhibition zone in millimeters $(\mathrm{mm})$. Data were collected and analyzed using the repeated measure ANOVA and T-test. The level of significance was set at $(\mathrm{p}<0.05)$.

Results: The antibacterial efficacy of the four studied dental cavity liners differed at different time intervals $(p<0.001)$, but there were no statically significant differences in the antibacterial activity against the two bacteria types $(\mathrm{p}=0.342)$, or between the four types of dental cavity liners $(\mathrm{p}=0.07)$.

Conclusion: According to the results of the present research, the antibacterial activities of Ionobond, Ionoseal, Ionosit and Vitrebond dental cavity liners were not significantly different and decreased over time.
\end{abstract}

Please cite this paper as: kazeroonizadeh N, Kazemian M, Mirzakoochaki P. An In-Vitro Study of the Antibacterial Efficacy of Cavity Liners Against Streptococcus Mutans and Lactobacillus Casei. J Res Dent Maxillofac Sci. 2017;2(2) :23-28 


\section{Introduction:}

Secondary carious lesion is the main factor that influences the longevity of dental restorations. ${ }^{(1)}$ Different bacterial species may be isolated from dental plaque. These bacteria are the main reasons of carious lesion and pulpal inflammation. ${ }^{(1,2)}$ Streptococcus mutans (S. mutans) and Lactobacillus casei (L. casei) are the two most frequently implicated bacteria in dental caries. ${ }^{(1)}$ Bacteria may remain under restorations such as crowns, bridges, veneers, inlays or onlays, as a result of incomplete removal of caries or due to microleakage. ${ }^{(3-5)}$

Caries removal is the first stage of tooth decay treatment. Many authors have reported that the bacterial flora is not completely removed from cavity walls during cavity preparation. ${ }^{(6,7)}$ Furthermore, microleakage may allow microorganisms to penetrate the gap between the filling material and dental tissue. ${ }^{(6,8)}$ Therefore, the antibacterial activity of dental materials is important from the clinical aspect, as it might inhibit recurrent caries. Glass Ionomers (GIs) have been used as cements, cavity liners and filling materials for over 20 years. ${ }^{(1)}$ These materials have antibacterial activity, which is generally attributed to the low $\mathrm{pH}$ during setting time and also to fluoride release. Fluoride-releasing restorative materials can decrease bacterial metabolism and proliferation. ${ }^{(4)}$ Release of strontium ions and fluoride may also create a synergistic antibacterial effect. (7) Resin-modified GIs (RMGIs) and compomers are also categorized as fluoride-releasing dental materials with essential components similar to those of conventional GIs. ${ }^{(4-8)}$ Compomers are resin composites which release fluoride. ${ }^{(5,9)}$ The amount of fluoride released from these resin composites is lower than that released from GI cements (GICs), and it is not adequate for bacterial growth inhibition. (7)

Manufacturers not only improve the mechanical and aesthetic properties of GIs, but they also try to ease their use and increase their antibacterial efficacy. ${ }^{(6)}$ Many studies have evaluated the antibacterial efficacy of different fluoride-releasing dental materials; ${ }^{(1-6)}$ however, new materials are introduced to the market every day in different forms including powder and liquid, capsulated, and one-component such as Ionoseal. ${ }^{(6)}$ Therefore, it is necessary to compare these products with the dental materials that have been previously introduced to the market. ${ }^{(4,5)}$ The aim of the present study was to compare the antibacterial activity of four fluoride-releasing dental cavity liners against S. mutans and L. casei.

\section{Materials and methods:}

In this in-vitro experimental study, the agar diffusion test was applied to compare the antibacterial activity of four dental cavity liners against S. mutans and L. casei. ${ }^{(1,2)}$ The brands, categories and manufacturers of the dental materials used in this research are presented in Table 1.

Table 1-Dental materials used in the present study

\begin{tabular}{lllll}
\hline Brand & Symbol & Category & Manufacturer & Country \\
\hline Ionoseal & ISE & $\begin{array}{l}\text { Light-curing one- } \\
\text { component glass } \\
\text { ionomer composite }\end{array}$ & VOCO & Germany \\
\hline Ionosit & ISI & $\begin{array}{l}\text { Light-curing } \\
\text { Compomer }\end{array}$ & DMG & United States \\
\hline Vitrebond & VB & $\begin{array}{l}\text { Light-curing glass } \\
\text { ionomer }\end{array}$ & 3M ESPE & Germany \\
\hline Ionobond & IB & $\begin{array}{l}\text { Chemically-curing } \\
\text { glass ionomer }\end{array}$ & VOCO & Germany \\
\hline Chlorhexidine & CHX & $\begin{array}{l}\text { Antimicrobial } \\
\text { mouthwash }\end{array}$ & Golrang & Iran \\
\hline
\end{tabular}

Indicator strains of S. mutans (ATCC35668) and L. casei (ATCC393) were obtained in the form of lyophilized culture (Biotechnology center of Islamic Azad University of Isfahan, Iran). They were grown separately in $15 \mathrm{ml}$ of Brain Heart Infusion (BHI) agar (Merck, Germany) at $37{ }^{\circ} \mathrm{C}$ for 24 hours. The broth was placed in an anaerobic environment imitating the physiologic characteristic of L. casei. Suspensions were prepared according to $0.5 \mathrm{McF}$ arland turbidity standard. Sterile saline $0.9 \%$ was used for 100 -fold dilution to create a suspension corresponding to $10^{6}$ colony-forming units according to McFarland scale.

The experimental specimens presented in Table 1 were made using a custom-built Teflon ring mold with the diameter of $7 \mathrm{~mm}$ and thickness of $2 \mathrm{~mm}$, except for Chlorhexidine (CHX). The four dental materials were placed inside the molds and were sandwiched between two Mylar 
Table 2. The studied dental materials and their instruction of use.

terial Instruction

oseal The light output should be a minimum of $500 \mathrm{~mW} / \mathrm{cm}^{2}$ for halogen polymerization and $300 \mathrm{~mW} / \mathrm{cm}^{2}$ for LED

device. Cure at least 20 seconds.

osit Cure at least 20 seconds for a thickness of about $1 \mathrm{~mm}$ with a light-curing unit that has an output of $450 \mathrm{~nm}$.

The light intensity should be at least $400 \mathrm{~mW} / \mathrm{cm}^{2}$.

rebond Cure at least 30 seconds for a thickness of about $2 \mathrm{~mm}$ with a 3M ESPE light-curing unit or other curing units

of comparable intensity.

obond The mixing time is approximately 30 seconds. Ionobond can be worked for approximately 1.2-2 minutes.

strips placed over a glass slab, and subsequently were cured according to the manufacturer's recommendations presented in Table 2. Afterwards, all the specimens were autoclaved (Iran Tolid Medical Industries Co, Iran) at $121{ }^{\circ} \mathrm{C}$ and 15 psi pressure for 15 minutes.

$10 \mu \mathrm{l}$ of aqueous $0.2 \% \mathrm{CHX}$ was poured on a sterile filter paper disc with the diameter of 7 $\mathrm{mm}$ and served as positive control.

$15 \mathrm{ml}$ BHI Agar medium (Merck, Germany) was poured evenly in each of the sterile Petri dishes to a thickness of $5 \mathrm{~mm}$. After the solidification of the culture medium at room temperature, $100 \mu \mathrm{l}$ of each bacterial suspension was added with the use of a micropipette and was spread uniformly using a sterile cotton swab. In each Petri dish, four discs of specimens and one filter paper of CHX were placed. The culture plates of S. mutans were incubated at $37{ }^{\circ} \mathrm{C}$ for 7 days; whereas, L. casei culture plates were incubated in a 5\% CO2 incubator. The antibacterial activity was evaluated at 24 and 48 hours, and at 7 days by measuring the diameter of the inhibition zone around the discs in millimeters ( $\mathrm{mm}$ ) using a digital caliper. $^{(1,10,11)}$ The experiment was repeated 6 times for each dental cavity liner, and the mean diameter of the inhibition zone was calculated for each dental material.

The data are presented as mean \pm standard deviation (SD). Statistical analysis was performed using the repeated measure ANOVA for intergroup differences and T-test. The level of significance was set at $(\mathrm{P}<0.05)$.

\section{Results:}

The mean diameters of the growth inhibition zones of the studied dental materials are shown in Table 3. The data related to the antibacterial activity of the tested dental materials were col

Table 3- The growth inhibition zones ( $\mathrm{mm})$

\begin{tabular}{|c|c|c|c|c|c|c|c|}
\hline \multirow[b]{2}{*}{ Bacteria } & \multirow[b]{2}{*}{ Liners } & \multicolumn{2}{|l|}{$\begin{array}{l}24 \\
\text { hours }\end{array}$} & \multicolumn{2}{|c|}{$\begin{array}{l}48 \\
\text { hours }\end{array}$} & \multicolumn{2}{|r|}{7 days } \\
\hline & & Mean & $\begin{array}{l}\text { Std. } \\
\text { deviation }\end{array}$ & Mean & $\begin{array}{l}\text { Std. } \\
\text { deviation }\end{array}$ & Mean & Std. deviation \\
\hline & Ionoseal & 8.35 & 1.19 & 7.97 & 1.22 & 7.80 & 0.96 \\
\hline \multirow[t]{5}{*}{ S. mutans } & Vitrebond & 9.67 & 1.63 & 8.90 & 1.16 & 9.03 & 1.26 \\
\hline & Ionobond & 9.50 & 1.76 & 8.57 & 1.52 & 8.43 & 1.50 \\
\hline & Ionosit & 8.35 & 1.05 & 7.24 & 0.50 & 7.07 & 0.83 \\
\hline & CHX & 18.83 & 2.40 & 21.27 & 3.17 & 18.26 & 2.07 \\
\hline & Ionoseal & 8.00 & 1.07 & 7.47 & 0.62 & 7.17 & 0.31 \\
\hline \multirow[t]{4}{*}{ L. casei } & Vitrebond & 9.65 & 1.88 & 8.26 & 1.44 & 8.04 & 1.22 \\
\hline & Ionobond & 9.16 & 1.20 & 8.07 & 1.15 & 7.58 & 0.99 \\
\hline & Ionosit & 8.52 & 1.71 & 8.06 & 1.21 & 7.68 & 1.16 \\
\hline & CHX & 23.72 & 1.41 & 23.62 & 2.00 & 23.37 & 2.16 \\
\hline
\end{tabular}


ure ANOVA. Vitrebond cavity liner showed the largest mean diameter of inhibition zone at each time interval; however, there were no statistically significant differences between the four types of dental cavity liners in terms of antibacterial potential $(p=0.07)$. Moreover, there were no statistically significant differences in the growth inhibition zones against the two bacterial species $(\mathrm{p}=0.342)$. The results indicated that the antibacterial activities of the four cavity liners differed at different time intervals $(\mathrm{p}<0.001)$. The overall antibacterial activity of the dental cavity liners significantly decreased over time $(p<0.001)$. The diameter of the inhibition zones against $\mathrm{S}$. mutans and L. casei at different time intervals in each group were compared using T-test.

\section{Discussion:}

The results of the present study indicated that the antibacterial efficacy of the studied dental cavity liners varied at different time intervals $(\mathrm{p}<0.001)$. Vitrebond cavity liner showed the largest mean diameter of the inhibition zone; however, there were no statistically significant differences between the four assessed cavity liners in terms of antibacterial potential $(\mathrm{p}=0.07)$. Moreover, there were no statistically significant differences in the growth inhibition zones of the cavity liners against the two bacterial species ( $\mathrm{p}=0.342$ ).

The primary purpose of restorative dentistry is to maintain or restore the function of the tooth by arresting caries or preventing their recurrence.

Caries removal is the first stage of tooth decay treatment. Many authors have declared that the bacterial flora is not completely removed from cavity walls during cavity preparation. ${ }^{(6,7)}$ Furthermore, microleakage may allow microorganisms to penetrate the gap between the filling material and dental tissue. ${ }^{(6,8)}$ Therefore, it is important to use restorative materials that can provide a long-term seal against cariogenic bacteria. ${ }^{(6)}$

The antibacterial activity of GICs is mostly attributed to fluoride release. ${ }^{(4,7)}$ However, some authors have stated that the antibacterial properties of GICs are more related to the low $\mathrm{pH}$ during setting time rather than fluoride release. ${ }^{(7)}$ Fluoride-releasing restorative materi- als can decrease bacterial metabolism and proliferation in the agar culture medium but may be incapable of preventing the rapid and spontaneous initial adhesion of bacteria. RMGICs also exhibit antimicrobial activity, which is due to the release of chemical components such as fluoride and metallic ions and also due to the low initial $\mathrm{pH} .{ }^{(7)}$ Release of strontium ions and fluoride may also create a synergistic antibacterial effect. $^{(7)}$ Compomers are resin composites which release fluoride. ${ }^{(5,9)}$ The amount of fluoride released from these resin composites is lower than that released from GICs, and it is not adequate for bacterial growth inhibition. ${ }^{(7)}$ In contrast, Dyract AP compomer was found to be more active against Streptococcus salivarius and Streptococcus sanguinis than Fuji IX GIC after 8 days, ${ }^{(9)}$ while other studies have suggested that its antibacterial effect is not long-lasting and ends after 24 hours. ${ }^{(9-11)}$ These results further highlight the contrasting views on the role of fluoride in the antibacterial activities of dental restorative materials.

A systematic review in 2015, which included 14 (500 treated lesions) of 113 identified studies, reported a disagreement between those clinical studies stating that the use of GIC or no lining is highly successful, and the other studies incorporated in this review which found MTA or antibacterial liners to be more suitable for exerting antibacterial effects. Eventually, it has been stated that the current evidence is inadequate to support certain cavity treatments before restoration. ${ }^{(8)}$

Antibacterial activity of GICs has attracted the attention of scientists since the 19th century until recent years. ${ }^{(12,13)}$ In spite of the fairly abundant literature regarding the issue, evaluation and comparison of the results is not simple. ${ }^{(6)}$ The methodology of these studies varies greatly, that in turn hampers the comparison of the results of these studies. Most authors, including us, have performed their experiments using the agar diffusion method; ${ }^{(6)}$ however, some recommended other techniques such as Direct Contact Test (DCT) ${ }^{(6)}$ The duration of studies also varied. The majority of them were short-term studies of 24 or 48 hours, and only a small number of them were conducted over a longer period of 7 days (similar to the present study). ${ }^{(6)}$ Also, there are some inconsistencies regarding the antibacterial activity of GICs observed in our study and studies of other authors, which can be attributed to the evaluated cements, bacterial strains and period of evaluation.

difference in terms of antibacterial activity according to the mean diameter of the inhibition zones $(p=0.07)$. However, the $p$-value was close to the signif- 
In the present research, four fluoride-releasing dental cavity liners were compared and showed no difference in terms of antibacterial activity according to the mean diameter of the inhibition zones $(p=0.07)$. However, the $p$-value was close to the significance level. Moreover, the overall antibacterial activity of the dental cavity liners significantly decreased over time $(p<0.001)$. The goal of this study was to compare the antibacterial activities of four different fluoride-releasing dental cavity liners. The agar plate diffusion test, which was adopted in the preset study, is the method of choice and the technique commonly used in medical laboratories to determine the antibacterial effect of different materials. $^{(1)}$

Vermeersch et al. used the agar diffusion test to compare the antibacterial behavior of six products against $\mathrm{S}$. mutans before and after setting, and concluded that all the studied GICs showed antibacterial activities; however, Vitrebond GIC demonstrated higher antibacterial potential because of its cytotoxic photoinitiator diphenyliodonium chloride. ${ }^{(1)}$ Shirani et al. also investigated the antimicrobial properties of Degufill (an ion-releasing resin composite), InTen-S (a hybrid resin composite), Compoglass (a compomer), and Vitremer (a RMGIC) against S. mutans and revealed that Vitremer showed significant antibacterial activity. ${ }^{(14)}$ In the present study, Vitrebond cavity liner showed a slightly higher antibacterial activity compared with the other cavity liners; however, the difference was not significant.

Many factors such as chemical composition, $\mathrm{pH}$, and release of fluoride and other ions can influence the antibacterial activity of dental materials. Chau et al. in 2015 reported that the antibacterial activity of GICs is closely related to their fluoride release rate through biofilm formation. ${ }^{(15)}$ Different inhibition zones may result from the sensitivity of bacterial species to ions releasing from dental materials. GICs have a low $\mathrm{pH}$ level during setting time that lasts for 24 hours. Some authors believe that this low $\mathrm{pH}$ increases the antimicrobial activity of dental materials. ${ }^{(8)}$

In the present study, the four evaluated dental cavity liners showed the highest anti- bacterial activity in the first 24 hours, which decreased during 7 days. This can be related to the low pH level of GICs during the first 24 hours. Vitrebond and Ionobond maintained their antibacterial activity after 7 days.

It has been well demonstrated that the release of fluoride from restorative materials is a very complex process, and can be affected by intrinsic variables such as fillers and formulations, and also by experimental factors such as storage media and the frequency of changing the storage medium. ${ }^{(15)}$

Further investigations are needed to compare various dental cavity liners with antibacterial properties, and to determine the antibacterial activity of fluoride-releasing dental cavity liners over a longer period of time, and also to evaluate these dental cavity liners in vivo.

\section{Conclusion:}

The four evaluated dental cavity liners (Ionobond, Ionoseal, Ionosit and Vitrebond) demonstrated antibacterial properties; however, none of them was statistically superior. These findings indicate that fluoride-releasing dental materials may play an important role in decreasing the number of bacteria in the prepared dental cavity walls.

\section{Conflicts of Interest:}

The authors of this manuscript certify that they have no conflicts of interest regarding this research.

\section{References:}

1.Vermeersch G, Leloup G, Delmée M, Vreven J. Antibacterial activity of glass-ionomer cements, compomers and resin composites: relationship between acidity and material setting phase. J Oral Rehabil 2005;32(5):368-74.

2. Marsh PD. Dental plaque as a biofilm and a microbial community - implications for health and disease. BMC Oral Health 2006;6 Suppl $1:$ S14.

3.Daugela P, Oziunas R, Zekonis G. Antibacterial potential of contemporary dental luting cements. Stomatologija 2008;10(1):16-21.

4.Featherstone JD. The caries balance:The basis for caries management by risk assessment. Oral health Prev Dent 2004;2 Suppl 1:259-64. 
5.American Dental Association Council on Scientific Affairs. Professionally applied topical fluoride: Evidenced-baced clinical recommendations. J Am Dent Assoc 2006;137(8):1151-9.

6.luczaj-Cepowicz E, Marczuk-Kolada G, Zalewska A, Pawińska M, Leszczyńska K. Antibacterial activity of selected glass ionomer cements. Postepy Hig Med Dosw 2014;68:23-8.

7.Seppa L, Korhonen A, Nutinnen A. Inhibitory effect on S.mutans by fluoride- treated conventional and resin-reinforced glass ionomer cements. Eur J Oral Sci 1995;103(3):182-5.

8.Schwendicke F, Tu YK, Hsu LY, Göstemeyer G. Antibacterial effects of cavity lining: A systematic review and network meta-analysis. J Dent 2015;43(11):1298-307.

9.Mousavinasab SM, Meyers J. Fluoride release by glass ionomer cements, compomer and giomer. Dent Res J (Isfahan) 2009;6(2):75-81.

10.Daugela P, Oziunas R, Zekonis G. Antibacterial potential of contemporary dental luting cements. Stomatologija 2008;10(1):16-21.

11. Prasad MP, Maradia MA. Antibacterial activity of Conventional and Modified Glass Ionomer Cement against Streptococcus mutans. J Appl Biotech 2014:2(3):17-20.

12.Loyola-Rodriguez JP, Garcia-Godoy F. Antibacterial activity of fluoride release sealants on mutans streptococci. J Clin Pediatr Dent 1996;20(2):109-11.

13.Loyola-Rodriguez JP, Garcia-Godoy F, Lindquist R. Growth inhibition of glass ionomer cements on mutans streptococci. Pediatr Dent 1994;16(5):346-9.

14. Shirani F, HavaeiA, Malekipour M. Sharafi M. Surface Antibacterial Properties of Four ToothColored Re-storative Materials. Jdt 2008;5(1):16.

15.Chau NP, Pandit S, Cai JN, Lee MH, Jeon JG. Relationship between fluoride release rate and anti-cariogenic biofilm activity of glass ionomercements. Dent mater 2015;31(4):100-8. 